\title{
Attitudinal Predictors of Potential Illegal Cross-Border Migration
}

\author{
Reidar Ommundsen ${ }^{*}, 1$, Kees van der Veer ${ }^{2}$, Krum Krumov $^{3}$, Plama Hristova ${ }^{3}$, Silvia Ivanova ${ }^{3}$, \\ Damyana Ivanova ${ }^{3}$ and Knud S. Larsen ${ }^{4}$
}

\author{
${ }^{I}$ University of Oslo, Forskningsveien 3A, 0373 Oslo, Norway \\ ${ }^{2}$ VU University Amsterdam, De Boelelaan 1105, $1081 \mathrm{HV}$ Amsterdam, The Netherlands \\ ${ }^{3}$ University of Sofia, Tsar Osvoboditel Blvd 15, Sofia, Bulgaria \\ ${ }^{4}$ Oregon State University, 1500 SW Jefferson Ave, Corvallis, OR 97331-8655, USA
}

\begin{abstract}
This paper reports on the relationship between attitudes toward illegal immigrants and illegal immigration, and people's private behavioural intention to immigrate illegally into a foreign country. The research was carried out in 2005 , in Bulgaria, a country with a net emigration rate, using a sample of 505 undergraduate Bulgarian students $(22.5 \%$ male; $M$ age $=23.3 ; S D=4.8$ ). A pool of 78 items assessed attitudes toward undocumented immigrants and evaluation of illegal migration. These two measures were used to predict potential undocumented immigration. Based on a factor analysis six subscales were identified and labelled: improvement of life, moral evaluation, courage to live, failure experienced in own country, expectations of benefits from illegal migration, and right to immigrate. Results of a multiple regression analysis explained 62 percent of the variance of the behavioural intention to migrate illegally into a foreign country. The analysis yielded the following factors: attitudes to improve life $(\beta=0.35)$, the moral evaluation of illegal immigrants $(\beta=-0.26)$, expectancies of benefits $(\beta=-0.19)$, the courage of migrants $(\beta=0.10)$, and seeing illegal immigration as a right $(\beta=$ 0.09), These findings support the hypothesis that attitudes may predict potential behaviour, the strongest predictor for undocumented migration being the urge to improve life, and moral evaluation of migrants.
\end{abstract}

Keywords: Attitudes, behavioural intentions, illegal immigration.

\section{INTRODUCTION}

Increased migration is a salient aspect of globalisation. People all over the world travel abroad in authorized ways using legitimate documents including tourist visas, invitations to seasonal workers by host governments, in pursuit of legitimate business, or as asylum seekers. Unauthorized migration occurs however when immigrants overstay their visas, or work without proper permits. For example, some immigrants disappear in the host country after rejection of their asylum applications, others slip across borders with false documents, or fail to register when required. Despite increasingly stringent immigration controls, a significant component of migration consists of people who travel to and stay in foreign countries illegally, see e.g. Bade [1]. According to the report of the Global Commission of International Migrations undocumented migration is one of the most controversial areas of policy and practice facing virtually all countries [2].

Attitudes toward immigration have mostly been studied in nationwide polls in 'receiving' countries, i.e. those with positive net immigration rates that receive more immigrants than they send abroad. The Netherlands and the Scandinavian countries are examples of receiving countries. Fewer studies have addressed attitudes toward unauthorized

*Address correspondence to this author at the Department of Psychology, University of Oslo, P.O. Box 1094, Blindern, 0317 Oslo, Norway;

Tel: +47 22845176; Fax: +4722845175;

E-mail: reidar.ommundsen@psykologi.uio.no migration in migrant 'sending' countries, i.e. countries like Bulgaria with a negative net emigration rate that send more immigrants than they receive [3]. The current study was carried out in Bulgaria in 2005. According to the World Factbook [4] the Gross Domestic Product (GDP) of Bulgaria is estimated as one half to one third of many European countries. Although it is possible to emigrate legally from Bulgaria since it attained EU membership in 2007, the fear of an east-west migration flow have caused several EU countries to impose labour mobility restrictions [5]. As a consequence illegal immigration has become the primary option for Bulgarians who want to make a living in a western country. Many young people are also experiencing low economic living standards and few opportunities for educational and professional advancement in Bulgaria [6]. These deprivations also motivate migration. Young people are also dissatisfied with the cultural and political changes that have occurred in Bulgaria over the last several decades. [7]. This country is also reported to have the lowest score on reported life satisfaction and happiness among EU member states [8], These disappointments have encouraged some Bulgarians to migrate abroad.

\section{PREVIOUS RESEARCH}

Several surveys have focused on the 'inclination' or intention to emigrate from Bulgaria. These studies report that more than half of the potential emigrants are below 30 years and highly educated. Although the intention to migrate is generally stronger with men than women the gender struc- 
ture has become more balanced [9]. In fact, among potential migrants younger women (15-29 years) with higher education outnumber men in wanting to settle permanently abroad [10]. So far the literature reports no studies, which have employed predictors of the intentions of Bulgarians to migrate illegally into a foreign country. The current study seeks to determine factors related to the intention to emigrate from Bulgaria.

Existing research on emigration reflects two levels of focus. One category of research concentrates on the sociological and macro-economic predictors of emigration [11, 12]. A second type focuses on the psychology of emigration including the personality characteristics of potential emigrants [13-17].

Sociological and macro-economic studies on emigration have revealed several factors that increase the level of largescale migration. Social surveys have estimated the level of potential future emigration by asking representative samples about their migration intentions [18]. Frieze et al. [13] point out however, that these studies tell us very little about why specific individuals living under comparable socio-economic conditions choose to migrate or stay at home. Moreover, there are validity problems when using self-assessed intentions to estimate future migration. For example Mintev, Boshnakov and Goev [9] states that it may be easy to claim intention to emigrate since in some communities, emigration brings status and prestige, however it may prove more difficult to actually emigrate and get a work permit in a new homeland. Such obstacles are clearly relevant when trying to forecast actual emigration behaviour. Since it is difficult to undertake direct studies of actual illegal migration, one option is to identify factors at the psychological level that influence the desire or intentions to emigrate. Of course, the utility of social psychological variables hinges on the ability of these factors to predict migration motivation and intentions which turn lead to subsequent behaviour. Nevertheless, in order to understand better why people emigrate, it may be useful also to gain information about psychological factors that may influence their intention to do so.

So far few studies have been carried out on determinants of the intention to emigrate at the individual level. Frieze et al. [13] surveyed 3200 university students from Central and Eastern European countries. The participants were asked which country they would like to live in for the major part of their adult life. The students who choose the response category "to live in another country rather than their own" were labelled as "leavers" (assuming they had a desire to emigrate), as opposed to "stayers" who indicated no desire to emigrate. The two groups were then compared on selected personality dispositions. Results of the study showed that those who wanted to emigrate scored higher on dispositions like Achievement and Power Motivation in combination with Work Centrality (i.e. seeing work as a central value in their lives. However, the aforementioned psychological dispositions could only account for a small percentage of the variance in the "desire to emigrate". Unfortunately the variable "desire" was measured by only one item possibly impacting the reliability of the results. In addition, since personality dispositions may not be easily changed they have low "engineering validity" [19]. Hence, personality dispositions are less susceptible to intervention if the aim is to change (e.g. reduce) the motivation of Bulgarians to leave their country.

In another study on emigration motivation of Bulgarian students Ådnanes [17] used three indicators to measure potential emigration. The respondents indicated on a 7-point scale how important it would be for them (a) to leave Bulgaria, (b) to migrate to a western country, and (c) to live abroad for a while. These three measures were combined into one index measuring "importance of emigration" for the respondents. Regression analysis showed that the index was predicted by several attitudinal measures, including the desire to be part of consumer culture, and by possessing a critical attitude toward the homeland political system. This study provided some improvement measuring motivation to emigrate. The predictor variables accounted for 26 percent of the variance in the dependent variable (importance of emigration), so there is obviously a need to look for additional factors to improve the prediction of potential emigration. Moreover, it is unclear to what extent the predictor variables in the Ånanes study had practical utility in influencing motivation to emigrate.

\section{THE CURRENT STUDY}

The present study sought to identify social psychological factors that predict the behavioural intentions of Bulgarians to migrate illegally into a foreign country. Although behavioural intentions in the Theory of Reasoned Action (TRA) and the Theory of Planned Behaviour (TPB) are considered the closest cognitive antecedent of a particular behaviour $[20,21]$ it is acknowledged that they are not a sufficient determinant for subsequent behaviour.

During the last decades several meta-analyses have been completed on the relationship between attitudes, behavioural intentions, and behaviour, (see Glasman and Albarracin [21] for an overview). Eckes and Six [22] examined the influence of measurement correspondence, the time interval between attitude and behaviour measures, the number of behaviour alternatives, and the behavioural domain. The researchers investigated the results of 501 studies, published in 59 journals between 1920 and 1990 and found the highest mean correlation between behaviour and behavioural intention $(\mathrm{r}=$ 0.54 ), a mean correlation between attitude and behavioural intention of $\mathrm{r}=0.51$, and the lowest between attitude and behaviour $(r=0.49)$. The presence of moderators in the relationship between attitude and behaviour account for some of the variance. Examples of moderators include the number of behaviour alternatives, for example where there are two alternatives the correlation is obviously higher than in the case where more alternatives are present. The manner of measuring the behavioural intentions also affects variance accounted for as in case of self-report where the correlation is much higher than with objective measurement. Also, the research domain may moderate the relationship of attitude to behaviour. For example, the correlation between attitude and behaviour (objectively measured) is high in the domain of political participation $(\mathrm{r}=0.68)$ and low in the domain of altruism $(\mathrm{r}=0.20)$. However, these correlations still leave many variables unaccounted for that might affect the relationship between attitude, behavioural intention and behaviour. 
The relationship between attitudes toward illegal migration and potential migration behaviour was not investigated in the Eckes and Six review [22]. The current research studied this relationship in a sample of university students since they are considered the part of the population that is more likely to emigrate than other population categories in Bulgarian society $[7,9,10]$. Although Bulgaria has been part of EU since 2007 some European countries continue to require work permits, which are strictly regulated allowing Bulgarians to apply for permits in only certain industries. Nevertheless undocumented migration continues. For example, in Ireland more than 5000 Bulgarians (and Romanians) appear to be working without the necessary permits [5].

The theories TPB, and TRA $[20,23,24]$ argue that in order to improve prediction it is necessary to ascertain how people evaluate the potential behaviour (e.g. outcome expectations). For example people may have positive attitudes toward the consumer culture in the West while at the same time having negative evaluations of the outcome of migrating illegally into another country. A negative evaluation is in turn assumed to discourage the development of migration intentions.

In order to improve the prediction of intentions to migrate it may be useful to move beyond personality dispositions, and the general attitudes researched by Ådnanes, and Frieze et al. [17, 13]. The focus of TPB and TRA is on the outcome expectations the person holds for his or her own behaviour. It may, however, be useful to move beyond this "individualistic" perspective. More specifically, Learning theory [25] demonstrates that the behaviour of other people may serve as models. For example, information about illegal immigrants who have succeeded abroad may lead others want to emulate their behaviour. People also compare themselves to reference groups [26]. If a reference group looked up to and accorded high social status, people may want to attain the same reputation as this group. Mintev et al. [9] note that illegal migrants may be praised in public discourse as courageous and brave making some willing to imitate such behaviour. On the other hand, if illegal immigrants are negatively portrayed as causing a threat to the common good, for example a brain drain from the country, the group may serve as a negative reference, thereby discouraging intentions to migrate. It is noteworthy that the status and evaluation of illegal immigration and migrants may be changed by the way they are portrayed in the media [27, p. 120].

The concepts of role models, and reference group are not explicitly addressed in the Theory of Reasoned Action, and the Theory of Planned Behaviour, yet these concepts may have utility as predictors of intentions

\section{MATERIALS AND METHODOLOGY}

\section{Item Pool}

Two sources provided the initial item pool employed in the study. Focus groups composed of survey experts in Bulgaria were consulted in order to generate attitude components considered salient in their country. Secondly, a literature search was conducted which yielded additional items, for example $[1,4,6,11,17]$.
The items were edited according to the a priori criteria of Edwards [28]. The pool consisted of statements describing various aspects of illegal immigration. In the final item-pool of 78 statements, 45 were keyed in the positive direction and 33 in the negative. Attitude components included negative consequences for society (e.g. brain drain), positive consequences for society (e.g. bringing new skills back home), positive consequences for family (e.g. remittances), the expectancies of illegal immigration (e.g. danger of being exploited in the new land), the view of unauthorized immigration as a human right (e.g. because of what is seen as an unfair distribution of wealth between nations), and the impressions and evaluation of people who choose to emigrate (e.g. in the process being viewed as heroic, or alternatively as betraying or abandoning one's own country).

Since linguistic and psychological equivalence is essential in cross-cultural assessment [29, 30] the item pool, and the Likert-type instructions were translated from English to Bulgarian independently by two translators using the conventional forward and backward translation procedure. The translation of the items proved fairly easy as reported by the Bulgarian bilingual co-researcher and independent translator. However, in addition, to augment cross-cultural equivalence $[30, \mathrm{p} .266]$ the item list was pre-tested by means of the Three-Step Test-Interview procedure [31-33]. This procedure involved administering the scale to a smaller number of people (in this case six Bulgarian students) who were asked to verbalize whatever considerations came into mind at the moment they responded to the attitude items. The three steps can briefly be described as follows.

1. Concurrent "think aloud" by the respondent aimed at collecting observational data

This step is strictly observational, the questionnaire is filled in while the respondent is thinking aloud. The argumentation of a certain answer to the questions, and other observational data, such as skipping questions, hesitating or correcting the chosen response category will also be part of the observational data. The interviewer makes notes to be used in the second step.

2. Focused interview aimed at remedying gaps in observational data.

This step is concerned with filling in gaps risen out of step one, such as incomplete answers, and questions about why someone stopped responding for a moment.

3. Semi-structured interview aimed at eliciting experiences and opinions.

In this step, the respondent is asked to express and explain his/her response behaviour, reflect on his/her own position on the topic - in our case illegal migration.

From this pre-test it was reported that the respondents did not have any problems with instructions, nor did they have any difficulty understanding the concepts. In the six months prior to data collection there had been frequent discussions of illegal migration in Bulgarian media (National TV and Radio, as well as in the newspapers). The media treatment may have contributed to the political saliency and development of response ready cognitive schema on this topic. 


\section{Participants}

In Bulgaria it is mainly people of both genders under the age of 30 and with a comparatively high educational level who express a wish to emigrate $[9,10]$. Therefore the 78 item-pool was administered in spring and fall, 2005 to a select sample of 505 undergraduate students from a wide range of studies enrolled at three universities in Sofia: Sofia University, University of World and National Economy, and Forest University. 22.5 percent were male $(M$ age $=23.3, S D$ $=4.8$ ). The statements were placed in random order in a selfcompletion questionnaire, each with five response options "strongly agree" (5), "agree" (4), "undecided" (3), "disagree" (2), "strongly disagree" (1). The data was collected in classrooms and lecture halls. Approval to conduct research was sought and granted by the universities according to their rules for research participants.

\section{Dependent Measure: Behavioural Intentions to Illegally Immigrate into a Foreign Country}

The Theory of Planned Behaviour and the Theory of Reasoned Action consider behavioural intentions to be the mediator connecting attitudes to behaviour [23, 24]. However, the social psychological literature on the attitude-behaviour relation shows that behavioural intention as a mediator and the antecedent of behaviour has alternatively been conceived as desires, self-predictions, wishes, or action-readiness, personal obligations to act, and affective evaluations of behaviour [22, 34-36]. However, these concepts are not at the same theoretical level as respondents may distinguish between for example desiring to do something and intending to do it (Perugini \& Bagozzi, [37]. Moreover, people may deny having intentions to emigrate in the near future, but nevertheless report a readiness or obligation to do so later should the situation become more feasible. Hence, measuring behavioural intention or actual plans to emigrate may place a limiting time frame on the results leading to an underestimation of potential emigration. In the present study a multi-item measure was used to assess potential illegal immigration into a foreign country:

1. I am ready to immigrate illegally into another country to benefit my family. (positive).

2. I would consider myself a looser if I left my country to immigrate illegally abroad. (negative).

3. I would feel like a failure if I had to immigrate illegally into another country. (negative).

4. My first obligation is to help my family, if necessary through illegal immigration. (positive).

The first item indicates a personal readiness to engage in illegal immigration, the next two statements express negative personal evaluations of behavioural intentions, and the fourth statement taps a personal norm to act. The four items, with the same five response options as used with the statements in the item pool, were scored so that a high value indicates high migration intention. Average scores were calculated. Cronbach's $\alpha$ coefficient for the scale for the scale was 0.80 $(M=2.95, S D=0.99)$.

\section{RESULTS}

\section{Examining the Structure of the Item Pool}

A principal component analysis with varimax rotation was employed in order to ascertain the structure of the item pool. Providing a ratio of 6 cases per item the pool exceeded the minimum requirement of 5 for factor analysis [38]. The suitability of data for factor analysis was determined according to conventional standards [39, 40]. Parallel Analysis [41] computes number of components with eigenvalues exceeding the corresponding criterion values for a randomly generated data matrix of the same size (78 variables x 505 respondents), hence six factors were found that also could be given a meaningful interpretation (eigenvalues $\geq 1.5$ ). This factor analysis, placing the cut off point for factor loadings at 0.50 , and excluding items with cross-loading on other factors $(>.30)$, yielded the following results:

Factor 1 accounts for $11.65 \%$ of the variance. The items have in common the enhancement of life and the factor is labelled Improve life and consists of 11 items of which the following 6 items were chosen:

1. Our citizens have a moral right to improve their lives through illegal immigration into another country.

2. Heroes do not stay home in poverty, but are prepared to immigrate illegally if necessary

3. It is justifiable that people try to find work illegally in another country when they cannot find it at home.

4. It is better to be the illegal immigrant, than to be disregarded in one's own country.

5. It is a human right to obtain a better life through illegal immigration into another country.

6. Possible prosperity in the future is not worth the risk of immigrating illegally into another country now (reversed weight).

Average scores were calculated. The $\alpha$ coefficient for the scale for the scale was $0.83(M=3.21, S D=0.80)$. High score indicates that illegal immigration is seen a legitimate way to achieve a better position in life.

Factor 2 accounts for $7.71 \%$ of the variance. It is mainly judgmental evaluation of the illegal migrant, and therefore is called Moral condemnation. This factor contains the following 7 items:

1. It is selfish to benefit from education in one's native country just to immigrate illegally.

2. When you immigrate illegally into another country you insult the honour of your native land.

3. People who immigrate illegally betray the values of their home country.

4. People who illegally immigrate are unpatriotic.

5. There is no justification for illegal immigration into another country.

6. Illegal immigrants do not betray the culture of their native country. (Reversed weight). 
7. Those who immigrate illegally into another country are betraying their own country.

Average scores were calculated. The $\alpha$ coefficient for the scale was $.88(M=3.41, S D=0.87)$. High score indicates that personal moral failings are attributed to people who emigrate illegally.

Factor 3 accounts for $4.20 \%$ of the variance. The factor covers items, which refer to the heroic nature of illegal immigration, and is labelled Courage to live (an alternative might be Risk taking). This factor consists of 4 items as follows.

1. Bulgarians immigrating illegally into another country are among the bravest.

2. It is the strongest who dare to illegally immigrate into another country.

3. Illegal immigration is the highest form of bravery.

4. Illegal immigrants end up living a meaningless life. (Reversed weight).

Average scores were calculated. The $\alpha$ coefficient for the scale was $0.81(M=2.23, S D=0.81)$. High score indicates that illegal immigrants are considered to be courageous and brave.

Factor 4 consists of items that negatively evaluate illegal migrants. It accounts for $3.97 \%$ of the variance and we call it Pejorative devaluation; or (failure in own country). It consists of the following 3 items:

1. Those who immigrate illegally into other countries are losers in their own countries.

2. Illegal emigrants are uneducated incompetents.

3. Illegal immigrants are restless vagabonds.

Average scores were calculated. The $\alpha$ coefficient for the scale was $0.80(M=1.93, S D=0.86)$. High score indicates that illegal immigrants are seen as losers in own country.

Factor 5 accounts for $3.53 \%$ of the variance. The items have in common the desire to rebuke rich countries and emphasize their duty to accept illegal immigrants. Therefore this factor is labelled Right to immigrate. The 4 items that load on the factor are the following.

1. Since rich countries exploit poor countries it is fair to immigrate illegally into a rich country.

2. The rich countries have a duty to accept illegal immigrants from my country.

3. The rich nations in the world should keep their borders open for illegal immigrants from poor nations.

4. An unemployed person should see it as his duty to travel, even illegally, to another country to find work.

Average scores were calculated. The $\alpha$ coefficient for the scale was $0.77(M=2.36, S D=0.78)$. High score indicates that rich countries are seen to have a duty to accept illegal immigrants.

Factor 6 accounts for $3.52 \%$ of the variance. The items all point to the lack of realism in placing one's hopes and expectations on illegal immigration, and therefore the factor is labelled Expectancies of benefits. The 3 items are as follows:

1. People who immigrate to another country illegally will not find the good life they are looking for.

2. Life does not get better by immigrating illegally into another country.

3. People who immigrate illegally are stupid to think that they will have a better life in their new country.

Average scores were calculated. The $\alpha$ coefficient for the scale was $0.69(M=2.37, S D=0.82)$. High score indicates that illegal immigrants are seen to have unrealistic hopes.

\section{Predictors of Behavioural Intentions to Illegally Immi- grate into a Foreign Country}

The mean intention to immigrate illegally into a foreign country was 2.95 on a scale from 1 (no intention at all) to 5 (strong intention). Zero order correlations between variables are provided in Table $\mathbf{1}$.

A simultaneous multiple regression analysis was carried out to evaluate the contributions of these six attitude scales

Table 1. Alpha Coefficients, and Correlations among the Predictor and Dependent Variables

\begin{tabular}{|c|c|c|c|c|c|c|c|c|c|}
\hline Scales & $\mathbf{A}$ & B & C & D & $\mathbf{E}$ & $\mathbf{F}$ & Dvar & G & Ag \\
\hline Improve life (A) & $(0.84)$ & & & & & & & & \\
\hline Courage to live (C) & $0.47 * *$ & $-0.27 * *$ & $(0.81)$ & & & & & & \\
\hline Failure in own country (D) & & $-0.36^{* *}$ & $0.47 * *$ & $-0.18^{*}$ & $(0.80)$ & & & & \\
\hline Right to migrate $(\mathrm{F})$ & $0.53 * *$ & $-0.32 * *$ & $0.53 * *$ & $-0.19 * *$ & -0.35 & $(0.69)$ & & & \\
\hline Dependent variable (Dvar) & & $0.63 * *$ & -0.61 & 0.45 & -0.41 & -0.57 & 0.53 & $(0.74)$ & \\
\hline Gender $(G)$ & -0.07 & -0.02 & 0.02 & -0.04 & 0.2 & -0.64 & -0.04 & () & -0.04 \\
\hline Age (Ag) & 0.07 & $-0.09 *$ & 0.07 & -0.00 & $-0.11 *$ & $0.09 *$ & -0.01 & & () \\
\hline
\end{tabular}


Table 2. Regression Analysis Summary for Attitude Variables Predicting Behaviour Intention to Migrate Illegally into a Foreign Country

\begin{tabular}{|c|c|c|c|c|c|}
\hline \multirow{2}{*}{ Variable } & \multicolumn{2}{|c|}{ Unstandardized Coefficients } & \multicolumn{2}{|c|}{ Standardized Coefficients } & \multirow{2}{*}{ Sig. } \\
\hline & $\underline{\mathbf{B}}$ & Std. Error & $\beta$ & $\mathbf{t}$ & \\
\hline Constant & 3.000 & 0.299 & & 10.040 & 0.000 \\
\hline Improve life & 0.381 & 0.047 & 0.345 & 8.086 & 0.000 \\
\hline Moral evaluation & -0.036 & 0.005 & -0.257 & -6.692 & 0.000 \\
\hline Courage/Risk taking & 0.039 & 0.011 & 0.099 & 2.791 & 0.005 \\
\hline Expectancies-Benefits & -0.072 & 0.004 & -0.186 & -5.083 & 0.000 \\
\hline Right to immigrate & 0.026 & 0.011 & 0.086 & 2.412 & 0.016 \\
\hline Gender & -0.040 & 0.063 & -0.020 & -0.661 & 0.490 \\
\hline Age & -0.112 & 0.062 & -0.054 & -1.756 & 0.069 \\
\hline
\end{tabular}

Note: Adjusted R Squared $=0.62 ;(\underline{N}=505)$.

(together with gender and age) on the intention to illegally immigrate. The results are shown in Table 2.

The factors Pejorative devaluation (failure in own country), Age and Gender showed no significant effect on intention to immigrate $(\mathrm{p}>0.05)$. The 5 remaining predictors ("To improve life", "Moral evaluation", "Courage to live/Risk taking", "Expectancies of benefits", and the "Right to immigrate") together explained $62 \%$ of the variance in the dependent variable.

The results of the regression analysis show that the more people consider the act of illegal migration justified in order to improve the standard of living for self and family, the greater the personal preparedness to immigrate illegally. Also, the more illegal migrants are perceived as immoral or egoistical, the less the personal readiness to engage in illegal immigration. Moreover, the more illegal immigrants are perceived as having unrealistic expectancies of benefits from migration, the lower the personal intention. The results also support the utility of social learning, and reference group concepts, as the more illegal immigration is seen as the acts of courageous persons, the greater the personal intention to illegally immigrate.

\section{DISCUSSION}

The present study explores the attitudes toward the act of immigrating illegally into a foreign country, and toward people who commit such behaviour. The aim was to see if and to what extent these attitudes could predict young Bulgarians' own behavioural intentions to immigrate illegally. The most important factor predicting intentions was attitudes toward illegal immigration justified as a means for improving a person's material standard of living $(\beta=0.35)$. This finding may reflect an "egocentric" desire to participate in the consumer culture of the west $[13,42]$. However, it may also indicate that Bulgarians see illegal immigration as a strong obligation in order to help family if needed [43], and it was the premise for including two intention statements in the dependent variable referring to helping family. The second most important factor is based on attitudes that attribute moral failings to people who emigrate $(\beta=-0.26$. The predictive strength of this factor was probably supported by discussions on Bulgarian National TV and Radio as well as the daily newspapers (e.g. Dnevnik), which discussed the possible negative consequences (e.g. brain drain) of Bulgarian emigration a few months before the data collection. The brain drain continues to be an issue in Bulgaria [44]. In any case emigration is generally seen both as a way to help self or family, but also as acting against the common good, and is therefore is a source of ambivalence for many potential emigrants.

The extent to which the respondents held negative expectations of the benefits derived from illegal immigration was related to a lower personal readiness to migrate $(\beta=-0.19)$. Outcome expectancies are considered essential for formation of behavioural intentions [23, 24] therefore future research needs to investigate what are the most powerful sources of (mis)information about migration outcomes.

Finally, attitudes related to the courage of migrants also turned out to have a minor, but statistically significant independent influence on behavioural intentions to emigrate $(\beta=$ -10). This finding provides an encouragement to investigate how images of (illegal) migrants develop, how they are maintained, and how they can be changed. Given that crossborder mobility of young women with higher education is comparable to men $[9,10]$ it was not surprising that gender proved to have no independent effect on migration intention. The age distribution was small and is probably the reason that this demographic factor did have a unique effect on emigration intentions.

\section{CONCLUSION}

The findings of the current study support the idea that improvement in predicting the intention to migrate illegally can be achieved by including measures of attitudes toward the act of illegal immigration and illegal immigrants. Illegal migration entails risks of exploitation (e.g. illegal working conditions, trafficking etc.) that may ultimately endanger the lives of the migrants [1, p. 34]. Consequently there is prac- 
tical utility for society in understanding the conditions that foster readiness to take personal risks. Knowledge of predictors of migration attitudes may also be useful in attempting to change the likelihood of illegal migration. Where attitudes toward illegal migrants and immigration are based on shared misconceptions (e.g. about benefits), public opinion may be changed by providing correct information. Information on what can realistically be expected when migrating illegally is a significant factor in potential migration. As noted, the utility of identifying predictors of motivation to emigrate hinges on the ability of intentions to predict subsequent behaviour. Given the fact that illegal migration is a political issue in Bulgaria, and referring to Eckes \& Six [22] who found the highest correlations between intentions and behaviour is in the political domain, studying predictors of intentions to emigrate has practical utility.

The novel contribution of the present study is the identification of a set of attitudinal predictors of illegal immigration that may apply to other countries as well. It remains for future studies to investigate what are the macro-economic and socio-cultural conditions that affect migration attitudes and prepares people psychologically for actual illegal migration.

\section{NOTES}

Portions of this research were presented at the $4^{\text {th }}$ International Black Sea Psychological Symposium on "Migration Processes and Globalisation Challenges" June 2009-07-01.

\section{ACKNOWLEDGEMENT}

The authors thank two anonymous referees for their helpful comments.

\section{REFERENCES}

[1] Bade KJ. Legal and illegal immigration into Europe: Experiences and challenges. Eur Rev 2004; 12: 339-75.

[2] Global Commision on International Migration. Migration in an Interconnected World: New Directions for Action. Genevaa, 2005. Available at: http://www.gcim.org/en/finalreport.html [accessed June 29. 2009].

[3] Ommundsen R, Van der Veer K, Hao LV, Krumov K. Larsen KS. Developing attitude statements toward illegal immigration: transcultural reliability and utility. Psychol Rep 2007; 100: 901-14.

[4] Central Intelligence Agency. CIA World Fact book 2006. Available at: https://www.cia.gov/cia/publications/factbook/index.html [accessed June 29.2009].

[5] Sofia Morning Star. Ireland crackdown on illegal Bulgarian workers. Available at: http://www.novinite,com/view_news.php? $\mathrm{id}=104685$ [accessed June 29. 2009].

[6] Rangelova R, Vladimirova K. Migration from central and eastern Europe: The case of Bulgaria. SEER - South-East Europe Review for Labour and Social Affairs (Issue 3) 2004; 7-30.

[7] Krumov K, Atanasova M, Petkova P, Ivanova D, Hristova P, Ivanova S. Dynamics of Motives toward Emigration of Bulgarian students. Paper presented at the $2^{\text {nd }}$ International Black Sea Psychological Symposium; Kiten, Bulgaria 2006, May 28-30.

[8] Eurofound. Second European Quality of Life survey - First findings (European Foundation for the Improvement of Living and Working Conditions 2009). Available at: http://www.eurofound. europa.eu/publications/htmlfiles/ef0852.htm [accessed March 13. 2010].

[9] Mintev V, Boshnakov V, Goev V. Who is leaving? Potential emigration from Bulgaria in the beginning of the XXI century. 2004, Appendix 2, Table 3.A. from Eldis database on the World
Wide Web: http://www.eldis.org/static/DOC17128.htm [accessed June 29. 2009].

[10] Rangelova R. Gender dimension of the new Bulgaria's migration: Comments on empirical data (Tables 3 and 4). Available at: http://aa.ecn.cz/img upload/36fc4ddc48d13ae0415c78ceae108bf5/ RRangelova_Gender_Dimensions.pdf [accessed March 13. 2010].

[11] Gächter A. The Ambiguities of Emigration: Bulgaria since 1988. International Migration Papers No. 39. Geneva: ILO. www.ilo.org/ public/english/protection/migrant/download/imp/imp39.pdf [accessed June 29. 2009].

[12] Ahearne A, Brücker H, Darvas Z, von Weizsäcker JK. Cyclical dimensions of labour mobility after EU enlargement. Paper prepared for the converence "EU Enlargement - 5 years after", Prague, 2 March, 2009. Available at: http://www.bruegel.org/ uploads/txt_btbruegel/wp_migration_300509_Final.pdf [accessed March 13, 2010].

[13] Frieze IH, Boneva BS, Sarlija N, et al. Psychological differences in stayers and leavers: Emigration desires in Central and Eastern European university students. Eur Psychol 2004; 9: 15-23.

[14] Carlson HM, Nilsen EL. Gender, psychological health, and attitudes toward emigration. Psychol Rep 1995; 76: 179-86.

[15] Tidrick K. Need for achievement, social class, and intention to emigrate in Jamaican students. Soc Econ Stud 1971; 20: 52-60.

[16] Tartakovsky E, Schwartz SH. Motivation for emigration, values, well -being, and identification among young Russian Jews. Int $\mathbf{J}$ Psychol 2001; 6: 88-99.

[17] Ådnanes M. Exit and/Voice? Youth and Post-communist citizenship in Bulgaria. Polit Psychol 2004; 25: 795-815.

[18] Eurofound. Survey examines migration post-accession. (European Foundation for the Improvement of Living and Working Conditions 2007). Available at: http://www.eurofound.europa.eu/ ewco/2006/10/ BG0610069I.htm [accessed June 29. 2009].

[19] Collins BE, Ashmore RD. Social Psychology. Social influence, attitude change, group processes, and prejudice. Menlo Park, Addison-Wesley 1970.

[20] Ajzen I, Fishbein M. The influence of attitudes on behaviour. In: Albarrcín D, Johnson BT, Zanna MP, Eds. The handbook of attitudes. Mahwah, NJ: Lawrence Erlbaum 2005; 173-221.

[21] Glasman LR, Albarracin D. Forming attitudes that predict future behaviour: A meta-analysis of the attitude-behaviour relation. Psychol Bull 2006; 132: 778-822.

[22] Eckes T, Six B. Fakten und fiktionen in der einstellungsverhaltens-forschung: Einen meta-analyse. Z Soz Psychol 1994; 253-71.

[23] Ajzen I. Fishbein M. Understanding Attitudes and Predicting Behaviour. Englewood Cliffs, NJ: Prentice-Hall 1980.

[24] Eagly S, Chaiken S. Attitude structure and function. In: Glibert DT, Fiske S, Linzey G, Eds. Handbook of Social psychology $4^{\text {th }}$ ed. New York, McGraw-Hill 1998; pp. 269-322.

[25] Bandura A. Social foundations of thought and action: A socialcognitive theory. Englewood.Cliffs, NJ: Prentice-Hall 1986

[26] Secord PF, Backman CW. Social Psychology $2^{\text {nd }}$ ed. New York: McGraw-Hill 1974.

[27] Mummendy A, Otten S. Aversive discrimination. In: Brown R, Gaertner S, Eds. Blackwell Handbook of Social Psychology: Intergroup processes, Oxford: Blackwell 2001; pp.112-132.

[28] Edwards AL. Techniques of attitude scale construction. New York, Appelton-Century-Crofts 1957.

[29] Berry JW, Poortinga YH, Segall MH, Dasen PR, Eds. Crosscultural psychology. Research and applications $2^{\text {nd }}$ ed. New York, Cambridge University Press 2002.

[30] Van de Vijver, FJR, Poortinga YH. Conceptual and methodological issues in adapting testes. In: Hambelton RK, Merenda PF, Spielberger CD. Eds. Adapting educational and psychological tests for cross-cultural assessment Mahwah, NJ: Erlbaum 2005; pp. 3963.

[31] Willis GB. Cognitive interviewing. A tool for improving questionnaire design. London: Sage 2005.

[32] Hak T, Van der Veer K, Jansen H. The Three-Step Test-Interview (TSTI): An observational instrument for pre-testing self-completion questionnaires. Survey Res Meth 2008; 2(3): 143-150.

[33] Hak T, Van der Veer K, Ommundsen R. An application of the Three-Step Test-Interview (TSTI): A validation of the Dutch and Norwegian Versions of the 'Illegal Aliens Scale. Int J Soc Res Meth 2006; 9: 215-227. 
[34] Armitage CJ, Connor M. Efficacy of the Theory of Planned Behaviour: A meta-analytic review. Br J Soc Psychol 2001; 40: 471-499.

[35] Abraham C. Beyond stages of change: Multi-determinant continuum models of action-readiness and menu-based interventions. Applied Psychology. An Int Rev 2008; 57(1): 30-41.

[36] Manstead SSR, Parker D. Evaluating and extending the Theory of Planned behaviour. In: Stroebe W Hewstone M, Ed. European review of social psychology, Chichester: Wiley 1995; vol. 6: pp. 69-95.

[37] Perugini M, Bagozzi RP. The distinction between desires and intentions. Eur J Soc Psychol 2004; 34: 69-84.

[38] Stevens JP. Applied multivariate statistics for the social sciences $4^{\text {th }}$ ed. Hillsdale NJ: Erlbaum 2002.

[39] DeVellis RF. Scale development: Theory and applications $2^{\text {nd }}$ ed. London: Sage 2003.

[40] Pallant J. SPSS Survival Manual $3^{\text {rd }}$ ed. Berkshire, Open University Press 2007.
[41] Watkins MW. Monte Carlo PCA for parallel analysis [Computer software]. State College, PA: Ed and Psych Associates. Available at: http://www.softpedia.com/getOthers/Home-Education/MonteCarlo-PCA-for-Parallel-Analysis.-shtml

[42] Van Meeteren M, Engersen G, van San M. Striving for a better position: Aspirations and the role of cultural, economic, and social capital for irrehular migrants in Belgium. Int Migrat Rev 2009; 43(4): 881-907.

[43] Slagsvold B, Daatland SO. Demographic factors and attitudes to filial responsibility - a comparative exploration. Paper presented at the UNECE conference "How generations and gender shape demographic change", Geneva, May $14^{\text {th }}-16^{\text {th }}$. Available at: http://www.unece.org/pau/_docs/ece/2008/ECE_AC31_2008_2 e adv.pdf [accessed June 29. 2009].

[44] Rowlands H. Howe to stop Bulgaria's brain drain? Editorial, Sofia News Agency, March 9, 2010. Available at: http://www.novinite. com/view_news.php?id=114002 [accessed March 13. 2010].

(C) Ommundsen et al.; Licensee Bentham Open

This is an open access article licensed under the terms of the Creative Commons Attribution Non-Commercial License (http: //creativecommons.org/licenses/by$\mathrm{nc} / 3.0 /$ ), which permits unrestricted, non-commercial use, distribution and reproduction in any medium, provided the work is properly cited. 